\title{
Delayed functional improvement after near-fatal bleeding complication following endobronchial valve therapy for emphysema
}

\author{
Sergio Baldi1, Francesco Coni', Paolo Solidoro', Giorgio Limerutti2, Massimo Baccega³, \\ Enrico Ruffini
}

\author{
1 Pulmonary Division, 2 Division of Radiology, 3 Division of Nuclear Medicine, Ospedale S. Giovanni Battista, \\ Turin, Italy
}

\begin{abstract}
Endoscopic treatment of emphysema is supported by different methods, including valves, coils and sealants. The mechanism is mainly related to volume reduction of targeted area. Endobronchial valves (EBV) appear the most studied method. In a multicentre randomised study, placement of unidirectional endobronchial valves resulted in a statistically significant functional improvement in the treated cohort compared to the control. Adverse events, occurring post procedure, included COPD exacerbations, haemoptysis, pneumothorax and pneumonia. In our centre we treated 30 patients, between January 2009 and February 2012, with variable improvement of lung function and only mild postoperative complications. The case we report here appears very interesting for the unusual near-fatal complication (massive alveolar haemorrage) followed by delayed strong functional improvement (FEV1 $+23 \%$; RV -18\%; 6MWD:+33\%) six months after the valve placement. This improvement could be attributable to the EBV procedure, but an alternative explanation is that the lung volume reduction may have been enhanced by the complication itself, as an effect of alveolar collapse.
\end{abstract}

\section{Case report}

Endoscopic treatment of emphysema is supported by different methods, including valves, coils and sealants [1-10]. The mechanism is mainly related to volume reduction of targeted area. Endobronchial

Corresponding author: Sergio Baldi, Pulmonary Division, Azienda Ospedaliera Città della Salute e della Scienza di Torino, C.so Bramante 88, 10126 Torino, Italy. E-mail: baldi_sergio@hotmail.com

Key words: Bronchoscopic lung volume reduction; lung volume reduction; emphysema.

Received for publication: 31 October 2013

Accepted for publication: 18 April 2014

(C) Copyright S. Baldi et al., 2015

Tipografia PI-ME Editrice, Italy

Monaldi Archives for Chest Disease Pulmonary Series 2015; 81:748

doi: 10.4081/monaldi.2015.748

This article is distributed under the terms of the Creative Commons Attribution Noncommercial License (by-nc 4.0) which permits any noncommercial use, distribution, and reproduction in any medium, provided the original author(s) and source are credited. valves (EBV) appear the most studied method. In a multicentre randomised study, placement of unidirectional endobronchial valves resulted in a statistically significant functional improvement in the treated cohort compared to the control [4]. Adverse events occurring post procedure included COPD exacerbations, haemoptysis, pneumothorax and pneumonia. In our centre we treated 30 patients, between January 2009 and September 2012, with variable improvement of lung function and only mild postoperative complications. The case we report here appears very interesting for the dramatic and unusual complication followed by delayed strong functional improvement. A 76 years old man with GOLD Stage IV emphysema and a BMI of 21 was admitted for EBV placement having undergone a period of pulmonary rehabilitation and optimisation of medical treatment according to our hospital practice. He suffered from controlled arterial hypertension and had an aortic valve replacement 12 years earlier at which time he was diagnosed with emphysema and he stopped smoking. His medication included a long acting anticholinergic, beta-agonist, inhaled corticosteroids, theophylline, furosemide, candesartan and warfarin. Before the procedure, his FEV1 was $0.69 \mathrm{~L}$ (27\% of predicted), RV 5.97L (226\% of predicted), 6MWT was 225 metres (53\% of predicted), and his MMRC Dyspnoea score was III. The BODE Index as proposed by B. Celli et al. [11] at the time of admission was 8. Chest X-ray demonstrated a significant flattening of the diaphragm with loss of lung parenchyma bilaterally. CT scan demonstrated advanced heterogeneous emphysema, with basal bulla in the right lower lobe (Figures $1,2)$, and with the right lung appearing more hyperinflated than the left; the fissure that separates the upper lobe from the other lobes appeared visible and complete. A ventilation/perfusion scan demonstrated a spotty bilateral distribution with reduced perfusion in the right lung (46\%) compared to the left lung. Platelet count was normal on admission.

The patient was changed from warfarin to subcutaneous heparin on admission. On the day of the procedure, heparin was discontinued and clotting time and INR was within the normal range. The procedure was performed in the endoscopy suite. The patient was sedated with opiates and midazolam and was spontaneously breathing. A local anaesthetic preparation was also administered. One large Zephyr Valve (Pulmonx, Redwood City, CA) was placed by flexible bronchoscopy into the targeted right upper lobe. Within 5 hours of the procedure, the patient became tachypnoeic (respiratory rate $>30 / \mathrm{min}$ ), arterial blood gases rapidly deteriorated ( $\mathrm{PaO} 250 \mathrm{mmHg}$ during oxygen delivered by reservoir, PaCO2 $70 \mathrm{mmHg}, \mathrm{pH} 7.20$ ) and he began to complain mild hemoptysis. Chest X-ray demonstrated the presence of a pneumothorax and $>50 \%$ loss of lung volume; a chest drain was immediately placed but his respiratory condition progressively worsened and the patient was transferred to the sub-intensive area.

A repeat chest X-ray revealed the lung re-expansion and a concomitant 2 large parenchymal opacifications in the same lung. A CT scan 


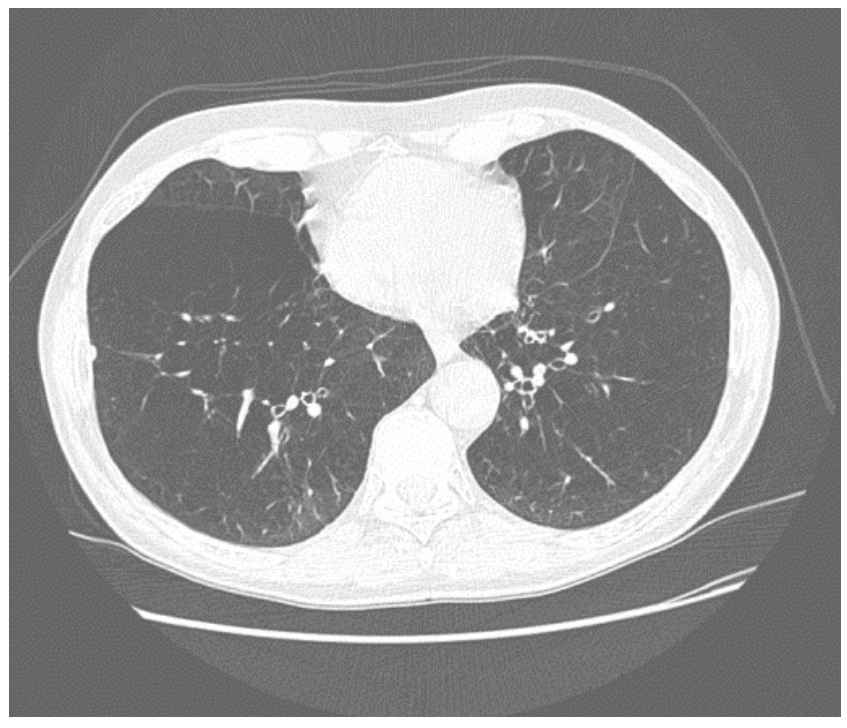

Figure 1. CT scan before treatment.

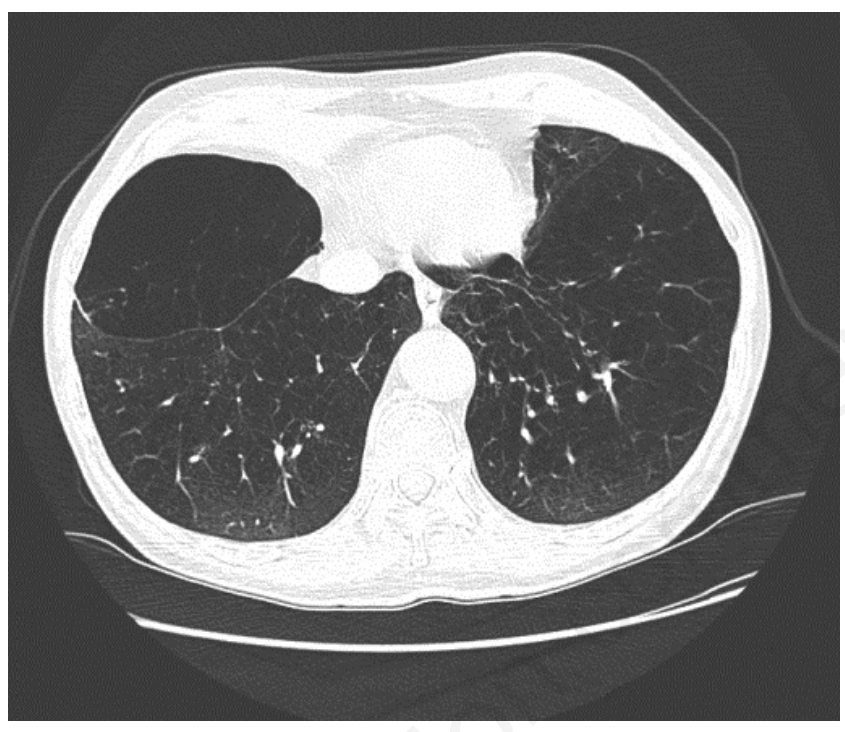

Figure 2. CT scan before treatment.

two days after procedure showed a $6 \mathrm{~cm}$ collection of liquid mixed with air in the bulla of the right lower lobe with a diffuse alveolar opacification of the entire lower lobe (Figure 3), and a further collection of dense fluid in the apical segment of the right lower lobe. A diagnosis of intra-parenchymal and intra-fissure haemorrhage was considered.
Non-invasive ventilation (NIV) was commenced. His respiratory condition remained critical, with persistent hypoxemia (PaO2 around 60 $\mathrm{mmHg}$ ) and hypercapnia (PaCO2 >60 $\mathrm{mmHg}$ ) under ventilation. He remained haemodynamically stable. A bedside bronchoscopy 48 hours after procedure revealed diffuse haemorrhage in the bronchial tree, mainly in the lower lobe, with moderate bleeding from the right upper lobe, where the valve appeared to operate well. Angiography of the bronchial artery was performed and confirmed bleeding from the right bronchial branch. Selective catheterisation of the superior bronchial artery of the right lung was performed followed by the release of microspheres (Embozene ${ }^{\circledR} 700$ micron) and by the insertion of one metal coil in order to stop the bleeding.

Subsequently, his respiratory condition remained stable but he developed signs of right heart failure and a transient dysarthria but no other neurological signs. The respiratory condition and general status of the patient progressively improved (Table 1) and 50 days after the valve placement the patient was discharged to a rehabilitation centre.

The patient was re-evaluated six months after the procedure. A CT scan at that time demonstrated a partial atelectasis of right upper lobe (Figure 4) and the reduction of the opacification of the right lower lobe bulla while the alveolar compartment appeared cleared. Pulmonary function tests, compared to preoperative values, were significantly improved, confirming the right indication for endoscopic bronchial valve treatment. FEV1 increased by $23 \%$ to $0.85 \mathrm{~L}$, RV reduced by $18 \%$ to $4.86 \mathrm{~L}$ and his 6MWT increased by $33 \%$ to $300 \mathrm{~m}$ (Table 1). BODE index improved from 8 to 6 .

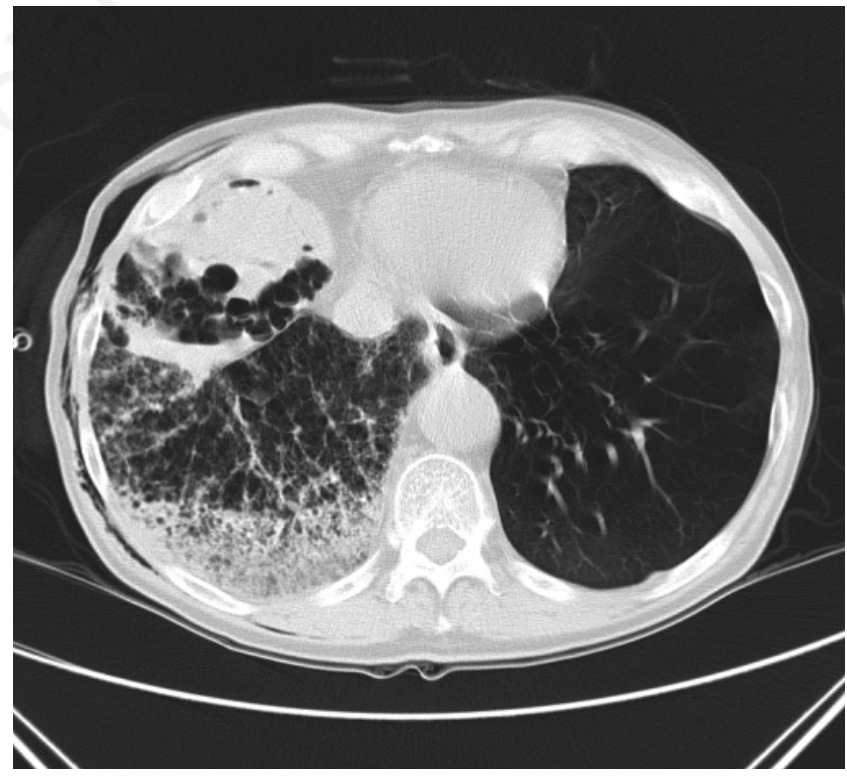

Figure 3. CT scan 2 days after procedure.

Table 1. Data are presented as absolute value and as percent of predicted.

\begin{tabular}{|c|c|c|c|c|c|c|c|c|c|c|}
\hline Variables & FEV1 & FVC & FEV1/VC & RV\% & TLC $\%$ & DLCO & $\mathrm{PaO} 2$ & $\mathrm{PaCO} 2$ & Pimax & 6MWD \\
\hline Preoperative data & $\begin{array}{l}0.69 \mathrm{~L} \\
(27 \%)\end{array}$ & $\begin{array}{l}3.25 \mathrm{~L} \\
(96 \%)\end{array}$ & $20 \%$ & $\begin{array}{c}5.94 \mathrm{~L} \\
(226 \%)\end{array}$ & $\begin{array}{c}9.36 \mathrm{~L} \\
(147 \%)\end{array}$ & $\begin{array}{c}5.8 \\
\mathrm{ml} / \mathrm{mmHg} / \mathrm{m} \\
(25 \%)\end{array}$ & $\begin{array}{c}64 \\
\mathrm{mmHg}\end{array}$ & $\begin{array}{c}40 \\
\mathrm{mmHg}\end{array}$ & $68 \%$ & $\begin{array}{c}225 \mathrm{mt} \\
(53 \%)\end{array}$ \\
\hline 50 days after procedure & $\begin{array}{l}0.70 \mathrm{~L} \\
(27 \%)\end{array}$ & $\begin{array}{l}1.44 \mathrm{~L} \\
(42 \%)\end{array}$ & $49 \%$ & & & & $\begin{array}{c}57 \\
\mathrm{mmHg}\end{array}$ & $\begin{array}{c}52 \\
\mathrm{mmHg}\end{array}$ & & \\
\hline 6 months after procedure & $\begin{array}{l}0.85 \mathrm{~L} \\
(34 \%)\end{array}$ & $\begin{array}{l}3.22 \mathrm{~L} \\
(96 \%)\end{array}$ & $26 \%$ & $\begin{array}{c}4.86 \mathrm{~L} \\
(184 \%)\end{array}$ & $\begin{array}{c}8.47 \mathrm{~L} \\
(134 \%)\end{array}$ & $\begin{array}{c}8.1 \\
(35 \%)\end{array}$ & $\begin{array}{c}62 \\
\mathrm{mmHg}\end{array}$ & $\begin{array}{c}41 \\
\mathrm{mmHg}\end{array}$ & $78 \%$ & $\begin{array}{c}300 \mathrm{mt} \\
(71 \%)\end{array}$ \\
\hline
\end{tabular}




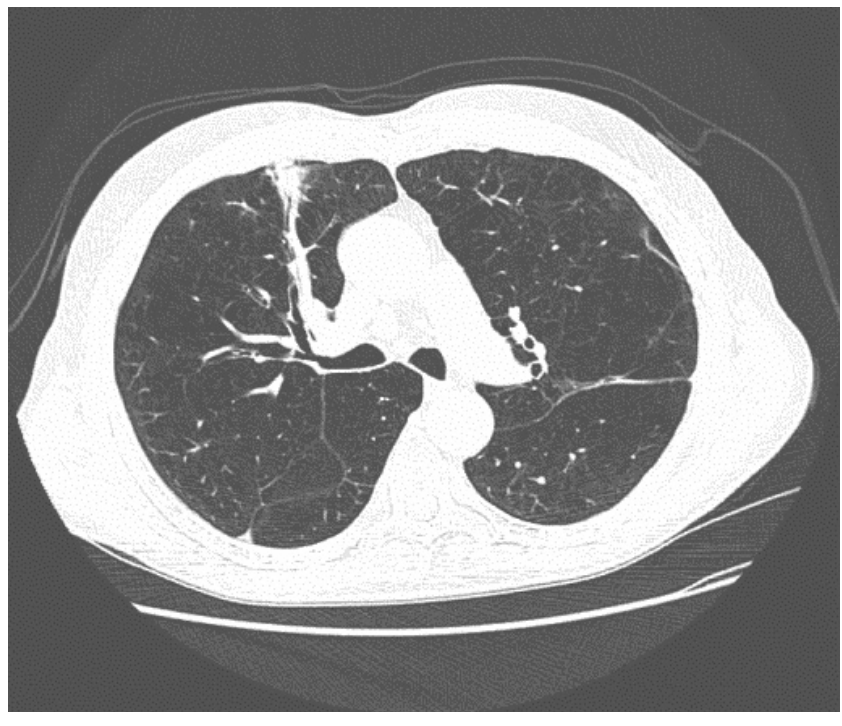

Figure 4. CT scan 6 months after procedure.

\section{Discussions and conclusions}

In a randomised study of endobronchial valves for advanced emphysema [4], valve placement resulted in a modest but clinically significant benefit but a larger benefit was observed in a subset of patients with heterogeneous emphysema and complete fissures. In the high heterogeneity sub-group, mean improvement FEV1 at 6 months was $10,7 \%$ and 6 MWT was $12,4 \%$; in the complete fissure subgroup FEV1 improvement was $16,2 \%$ and 6 MWD 7,7\%. COPD exacerbations, haemoptysis, pneumothorax and pneumonia occurred more commonly in the treatment group compared to the control group of standard medical care in the first three months but were comparable during the period from three to twelve months [4]. In our centre we treated $30 \mathrm{pa}-$ tients using unidirectional bronchial valves (Zephyr EBV (Pulmonx; Redwood City, CA) with modest improvement of lung function (mean FEV +7\%; mean RV -8\%; 6MWD +6\%) and mild postoperative complications (pneumothorax in 2, haemoptysis in 1 and acute exacerbation of COPD in 1); results and complications being similar to the complete cohort analysis reported by Sciurba FC et al. [4]. The present case reports a very unusual and dramatic complication after valve placement, not only due to pneumothorax but also due to massive and diffuse bleeding in the fissure and inside the bulla, as well as in the alveolar compartment. The previous anticoagulation therapy could be considered a risk factor although the clotting time was in normal range at the time of the procedure. The presence of a basal bulla in the right lower lobe adjacent to the treated lobe may have increased the risk of the development of a pneumothorax post procedure. A possible explanation of the dramatic haemorrhage could be the rapid re-expansion of the lung after chest drainage, similarly to a pulmonary oedema observed after the expansion of the lung. Despite this complication, this patient obtained a substantial clinical improvement with an increase in FEV1 of $23 \%$, reduction in $\mathrm{RV}$ of $18 \%$ and improvement in $6 \mathrm{MWT}$ of $33 \%$ at six months post procedure. In addition to the therapeutic effect from valve therapy, it is possible that the intraparenchymal haemorrhage provided a biological lung volume reduction mechanism whereby the haemorrhage induced an inflammatory reaction resulting in alveolar collapse. However, it should be noted that the distribution of the blood was not localised to the target lobe.

In conclusion, this patient experienced an unusual complication with massive bleeding following EBV therapy. However, this patient subsequently obtained a very good functional improvement, which could be attributable to the EBV procedure, but an alternative explanation is that the lung volume reduction may have been enhanced by the complication itself. This case also supports the view that an early and dramatic complication such as severe pulmonary hemorrhage does not preclude the success of procedure.

\section{References}

1. Wood DE, McKenna RJ Jr, Yusen RD, et al. A multicenter trial of an intrabronchial valve for treatment of severe emphysema. J Thorac Cardiovasc Surg 2007;133:65-73.

2. Snell GI, Holsworth L, Borrill ZL, et al. The potential for bronchoscopic lung volume reduction using bronchial prostheses: a pilot study. Chest 2003;124:1073-80.

3. Venuta F, de Giacomo T, Rendina EA, et al. Bronchoscopic lungvolume reduction with one-way valves in patients with heterogenous emphysema. Ann Thorac Surg 2005;79:411-6.

4. Sciurba FC, Ernst A, Herth FJF, et al. A randomized study of endobronchial valves for advanced emphysema. New Eng J Med 2010;363:1233-44.

5. Herth FJ, Eberhard R, Gompelmann D, et al. Bronchoscopic lung volume reduction with a dedicate coil: a clinical pilot study. Ther Adv Respir Dis 2010;4:225-31.

6. Refaely Y, Dransfield M, Kramer MR, et al. Biologic lung volume reduction therapy for advanced homogeneous emphysema. Eur Respr J 2010;36:20-7.

7. Criner GJ, Pinto-Plata V, Strange C, et al. Biologic lung volume reduction in advanced upper lobe emphysema: phase 2 results. Am J Respir Crit Care Med 2009;179:791-8.

8. Ernst A, Anantham D. Bronchoscopic Lung Volume Reduction. Sem Thor Surg 2010;22:330-7.

9. Ninane V, Geltner C, Bezzi M, et al. Multicentre European study for the treatment of advanced emphysema with bronchial valves. Eur Respir J 2012;39:1319-25.

10. Herth FJF, Horten M, Valipour A, et al. Efficacy predictors of lung volume reduction with Zephyr valves in a European cohort. Eur Respir J 2012;39:1334-42.

11. Celli BR, Cote CG, Marin JM, et al. The body-mass index, airflow obstruction, dyspnea, and exercise capacity index in chronic obstructive pulmonary disease. N Engl J Med 2004;350:1005. 